\title{
Stretched Size of Atrial Septal Defect Predicted by Intracardiac Echocardiography
}

\author{
Ming-Chih LIN, ${ }^{1-3} \mathrm{MD}$, Yun-Ching Fu, ${ }^{1,2} \mathrm{PhD}$, Sheng-Ling JAN, ${ }^{1,2} \mathrm{MD}$, Chi-Lin Ho, ${ }^{2} \mathrm{MD}$, \\ and Betau Hwang, ${ }^{1}$ MD
}

\section{SUMMARY}

The stretched size of an atrial septal defect (ASD) is important for device selection during transcatheter closure. However, balloon sizing carries potential risks such as hypotension, bradycardia, or laceration of the atrial septum. The aim of the present study was to investigate the accuracy of the predicted stretched size of ASD by intracardiac echocardiography (ICE).

From December 2004 to November 2007, 136 consecutive patients with single secundum type ASD undergoing transcatheter closure of their defect using the Amplatzer septal occluder under ICE guidance were enrolled for analysis.

There were 43 males and 93 females. The age ranged from 2.2 to 79.1 years with a median age of 13.4 years. The body weight ranged from 12.1 to $93.2 \mathrm{~kg}$ with a median body weight of $45.8 \mathrm{~kg}$. The stretched size of ASD measured by a sizing plate was considered as the standard. ASD sizes measured by ICE in bicaval and short-axis views predicted the stretched size by formulae derived from linear regressions. The predicted stretched sizes obtained using 2 formulae, $1.34 \times \sqrt{\text { bicaval } \times \text { short axis }}$ (formula 1 ) and $1.22 \times$ larger diameter (formula 2), exhibited good agreement with the standard stretched size with Kappa values of 0.91 and 0.90 , respectively. The accuracy rate of predicted stretched sizes within $2 \mathrm{~mm}, 3 \mathrm{~mm}$, and $4 \mathrm{~mm}$ range of the standard size were $32.8 \%, 45.4 \%$, and $57.7 \%$ (formula 1 ) and $33.1 \%, 50 \%$, and $63.2 \%$ (formula 2).

The stretched size of ASD predicted by ICE exhibited good agreement with the standard stretched size. This prediction provides helpful information, especially if balloon sizing cannot be adequately performed. (Int Heart J 2010; 51: 56-59)

Key words: Atrial septal defect, Heart catheterization, Intracardiac echocardiography, Transcatheter closure

$\mathrm{T}$

ranscatheter closure of a secundum type atrial septal defect (ASD) using the Amplatzer Septal Occluder (ASO, AGA Medical, Golden Valley, MN) is a standard procedure nowadays. ${ }^{1-3)}$ During the procedure, an accurate determination of the defect size is crucial for successful device deployment. The stretched size of ASD measured by balloon sizing is the standard method for device selection. However, it carries potential risks of hypotension, bradycardia, or laceration of the atrial septum. ${ }^{4,5)}$ Furthermore, it is difficult to perform if the ASD is large. In this situation, prediction of the stretched size of ASD without balloon sizing becomes critical.

Traditionally, transesophageal echocardiography (TEE) was used for assessing ASD size, device position, and possible residual shunts. ${ }^{2,3)}$ However, TEE has certain drawbacks such as needing general anesthesia and possible esophageal trauma. Through more than a decade of development, intracardiac echocardiography (ICE) is proved to be safe, effective, and user-friendly to guide transcatheter closure of ASD without the need for general anesthesia. ${ }^{6-10)}$ The aim of this study was to investigate the accuracy of the predicted stretched size of ASD by ICE.

\section{Methods}

From December 2004 to November 2007, 136 consecutive patients with single secundum type ASD undergoing transcatheter closure of their defect using the ASO were enrolled for analysis. There were 43 males and 93 females. Patient age ranged from 2.2 to 79.1 years with a median age of 13.4 years. Body weight ranged from 12.1 to $93.2 \mathrm{~kg}$ with a median of $45.8 \mathrm{~kg}$.

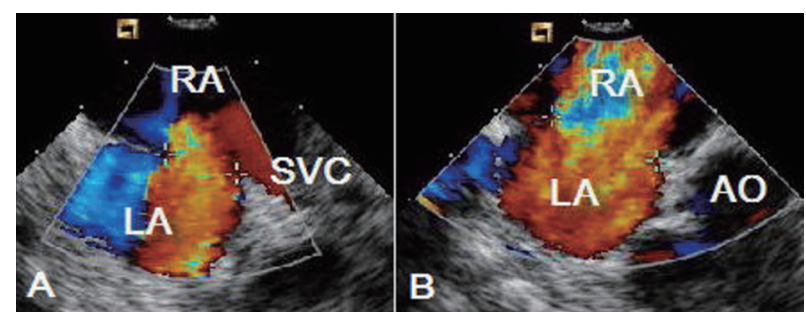

Figure 1. Images of intracardiac echocardiography in (A) bicaval view and (B) short axis view. AO indicates aorta; RA, right atrium; LA, left atrium; and SVC, superior vena cava.

From the ${ }^{1}$ Department of Pediatrics and Institute of Clinical Medicine, National Yang-Ming University, Taipei, ${ }^{2}$ Division of Pediatric Cardiology, Department of Pediatrics, Taichung Veterans General Hospital, Taichung, and ${ }^{3}$ Institute of Preventive Medicine, National Taiwan University, Taipei, Taiwan.

Address for correspondence: Yun-Ching Fu, PhD, Department of Pediatrics, Taichung Veterans General Hospital, 160, Sec 3, Chung-Kang Road, Taichung 40705, Taiwan

Received for publication May 1, 2009

Revised and accepted September 25, 2009. 
Table I. R-Square Values and Coefficients of Linear Regression Models

\begin{tabular}{lccc}
\hline Factors & R-square & Coefficients & $\begin{array}{c}\text { Agreement } \\
\text { (95\% confidence interval) }\end{array}$ \\
\hline ICE-bicaval view & 0.934 & 1.38 & \\
ICE-short-axis view & 0.941 & 1.25 & \\
$\sqrt{\text { bicaval } \times \text { short axis }}$ & 0.946 & 1.34 & $0.90(0.85 \sim 0.93)$ \\
ICE (larger diameter) & 0.954 & 1.22 & $0.91(0.88 \sim 0.94)$ \\
\hline
\end{tabular}

Model: sizing plate size $=$ coefficient $\mathrm{x}$ factor

Table II. Accuracy of Predicted Stretched Size of ASD

\begin{tabular}{lcc}
\hline \multirow{2}{*}{ Range } & $1.34 \times$ & $1.22 \times$ larger diameter \\
& $\sqrt{\text { bicaval } \times \text { short axis }}$ & \\
\hline $2 \mathrm{~mm}$ & $32.8 \%$ & $33.1 \%$ \\
$3 \mathrm{~mm}$ & $45.4 \%$ & $50.0 \%$ \\
$4 \mathrm{~mm}$ & $57.7 \%$ & $63.2 \%$ \\
\hline
\end{tabular}

ASD size measurement: The device closure protocol has been described in detail in previously published papers. ${ }^{1,11-13}$ The procedure was guided by ICE using a 10F AcuNav catheter (Siemens Inc., Mountainview, California, USA) which was introduced through an $11 \mathrm{~F}$ femoral sheath. ASD size was measured in both bicaval (Figure 1A) and shortaxis views (Figure 1B) of color Doppler mapping. Next, a sizing balloon (AGA Medical Corporation, Golden Valley, Minnesota, USA) 24 or $34 \mathrm{~mm}$ in size was introduced to stretch the defect until a waist appeared. The sizing balloon was deflated, taken out and then inflated again with the same amount of contrast medium. The ASD stretched size determined by a sizing plate (AGA Medical Corporation) was considered the standard.

Statistical analysis: Linear regression was applied to analyze the ASD sizes measured by ICE and generated prediction formulae for the stretched sizes. Cook's distance and centered leverage values were inspected for each patient to see if there were outliers or influential cases. The agreement between predicted and standard values was inspected by intraclass correlation coefficient (using a consistency definition). The factors affecting correct prediction were analyzed by multiple logistic regressions. The variables were selected by the forward method using likelihood ratio tests. SPSS 13.0 for Windows was applied for statistical analysis. Statistical significance was assumed to be a $P$ value less than 0.05 .

\section{RESUlts}

Prediction models: Assuming the defect was oval in shape, we used the ASD sizes both in bicaval and short-axis views. Linear regression produced the following formula; ASD Stretched size $=1.34 \times \sqrt{\text { bicaval } \times \text { short axis }}$ (formula 1$)$. For simplicity, we only used the larger size by ICE and constructed a second formula; 1.22 x larger diameter (formula 2). The model R-square, coefficients, and agreement are summarized in Table I. The scatter plots between predicted values and sizing plate size are summarized in Figure 2A
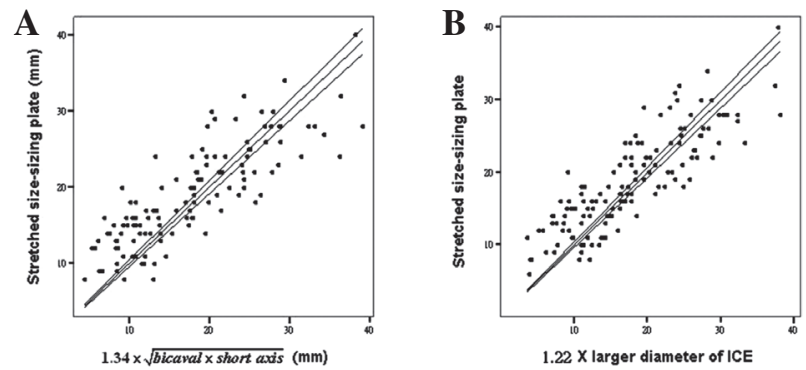

Figure 2. The scatter plot between balloon stretched size and (A) $1.34 \sqrt{\text { bicaval } \times \text { short axis }}$ and (B) $1.22 \times$ larger diameter by intracardiac echocardiography.

and Figure 2B. In the scatter plots, we could easily find that both models were quite stable because of no significant outliers. The extreme values were also inspected by Cook's distance and centered leverage value. All Cook's distances were under 1 and no centered leverage value was greater than 0.5. Both formulae exhibited good agreement (greater than 0.9 ) between predicted and standard values.

Accuracy of the predicting model: The residual values were evenly distributed and not magnified for the larger defects. The accuracy of prediction is summarized in Table II. The accuracies of predicted stretched sizes within ranges of 2 $\mathrm{mm}, 3 \mathrm{~mm}$, and $4 \mathrm{~mm}$ of the standard size were $32.8 \%$, $45.4 \%$, and $57.7 \%$ (formula 1 ) and $33.1 \%, 50 \%$, and $63.2 \%$ (formula 2). We also attempted to identify factors which had an impact on the prediction accuracy. A binary logistic regression model was adopted for this purpose. Body weight, height, body surface area, Qp/Qs (pulmonary flow versus systemic flow), and balloon stretch size were all tested in the model. None had a significant impact on the prediction accuracy.

\section{Discussion}

This study developed two novel formulae to predict the stretched size of ASD. Both were in good agreement with the standard size measured by a balloon sizing. The main goal of this study was to identify equations with which clinicians can predict ASD size by ICE measurements.

Previous studies reported that either TEE or ICE would underestimate ASD stretched size..$^{3,12,14,15)}$ This is because most ASD have pliable and redundant rim tissues. Although some authors have suggested that the balloon stretched size overestimates the real size, ${ }^{16)}$ balloon stretch size is still 
being adopted as a gold standard until a new consensus is reached in the future. In this study, we found that the balloon stretched size may be 22 to $34 \%$ larger than the size measured by echocardiography. The difference is a little larger than previously suggested (2-4 mm), especially for large ones. ${ }^{3,12,14,17)}$ This is quite reasonable because as the defects become larger, the pliable rim should also become larger. Zanchetta made the same observations and suggested selecting a device size 10-20\% larger than ICE measurement. ${ }^{15)}$ Zanchetta also suggested predicting ASD diameter using the square root of two ICE measurements plus each other to predict fossa ovalis area. ${ }^{15,18)}$ In our study, we obtained the same findings and proved them by statistical methods. This approach is quite reasonable because most of the defects are in the oval shape and the device would stretch the defects to equivalent circles.

Nowadays, ICE is gradually accepted as a good alternative to TEE. In comparison with TEE, it has several major advantages. First, the patient tolerance is good. General anesthesia and endotracheal tube insertion are usually unnecessary. Thus, the procedure time could be significantly shortened. Second, the exposure of TEE personnel to ionizing radiation can be avoided. Third, it can provide equivalent or superior image quality for operators. Finally, there is a higher probability that TEE will interfere with the fluoroscopy due to its larger profile and position of the esophagus. ${ }^{9,15,19,20)}$ Certainly, ICE has some drawbacks. First, it needs another vascular access which is at least $9 \mathrm{~F}$ and via a femoral vein. This could cause vascular injury in small children. The theoretical rate of infection or hematoma at the puncture sites would rise. In our series, we puncture bilateral femoral veins if the patient's body weight is less than $30 \mathrm{~kg}$ to avoid vascular injury. This would limit the use of ICE in small children if only one femoral vein is available for procedures. Second, because the ICE probe is disposable, the cost would rise. Third, introducing another catheter into the right atrium may cause perforation of the inferior vena cava or right atrium.

One of the main goals of this study was to discuss the possibility of omitting sizing balloon procedures. Sizing balloon is a potentially harming procedure. Laceration of the defects has been reported. ${ }^{21,22)}$ In our own experience, we have encountered a cardiac arrest event when left ventricle inflow was incidentally obstructed by a sizing balloon. The rough surface and relatively large profile of the sizing balloon itself could also cause blood vessel damage and hematoma at puncture sites. In this study, balloon stretch size could not be correctly predicted within $4 \mathrm{~mm}$ in approximately one-third of the patients. The random error may come from variation in the size of the pliable rim for different patients. However, we believe it is still possible to use ICE alone to complete the procedure. First, balloon sizing often over-stretches the defects. ${ }^{17)}$ Whether over-stretching the defect is necessary is still a controversial issue. Second, the ASO is a flexible self-centering device which provides a certain "safe" zone for sizing determination. Third, ASO is retractable when operators find it is inappropriate in size. In fact, when closing ventricle septal defects, the device size was determined only by TEE. ${ }^{23)}$ Successful deployment of ASO in adult patients using ICE alone has been reported. ${ }^{15,18)}$ Further trials may be needed to elucidate this issue in pediatric patients.

ICE has been widely accepted by interventional cardiologists as an alternative image tool to TEE. ${ }^{7-10)}$ In fact, many cardiologists prefer ICE to TEE, not only because there is no need for general anesthesia, but also its better image qualities. Furthermore, ICE can provide a better view of the inferior septum which TEE cannot provide. ${ }^{8,9)}$ There are two studies comparing ICE and TEE in the literature, and both reported excellent agreement. ${ }^{6,10)}$ For the reasons mentioned above, we do not believe further randomized trials between TEE and ICE are urgently needed. As to the necessity of balloon sizing, Zhu, et al reported good agreement between 3-D TEE, 2-D TEE, and balloon stretch size. ${ }^{17)}$ In our study, we also demonstrated good agreement between ICE and balloon stretch size after adjustment by our proposed equations. In other words, balloon stretch size could be predicted by TEE or ICE. Zanchetta, et al also demonstrated the feasibility of using ICE alone without balloon sizing in a small series. ${ }^{15,18)}$ However, long-term outcome reports are still lacking. A larger series and randomized trials might be needed to evaluate the benefit and if there is potential harm in deploying ASO without balloon sizing.

In summary, " $1.34 \times \sqrt{\text { bicaval } \times \text { short axis }}$ " or " 1.22 x larger diameter" provide a basic estimate of ASD stretch size. Although the random error is still large, these formulae could provide operators extra information when performing the procedure. It is especially useful when the sizing balloon procedure could not be easily performed due to limited vascular access or the condition of the patient.

\section{REFERENCES}

1. Lin MC, Fu YC, Jan SL, et al. Transcatheter closure of secundum atrial septal defect using the Amplatzer Septal Occluder: initial results of a single medical center in Taiwan. Acta Paediatr Taiwan 2005; 46: 17-23.

2. Butera G, De Rosa G, Chessa M, et al. Transcatheter closure of atrial septal defect in young children: results and follow-up. J Am Coll Cardiol 2003; 42: 241-5.

3. Omeish A, Hijazi ZM. Transcatheter closure of atrial septal defects in children \& adults using the Amplatzer Septal Occluder. J Interv Cardiol 2001; 14: 37-44.

4. Chessa M, Carminati M, Butera G, et al. Early and late complications associated with transcatheter occlusion of secundum atrial septal defect. Am Coll Cardiol 2002; 39: 1061-5.

5. Sivasankaran S, Harikrishnan S, Narayanan N, Jaganmohan T. Laceration of atrial septum during balloon sizing of atrial septal defect. Eur J Echocardiogr 2007; 8: 89-90.

6. Hijazi Z, Wang Z, Cao Q, Koenig P, Waight D, Lang R. Transcatheter closure of atrial septal defects and patent foramen ovale under intracardiac echocardiographic guidance: feasibility and comparison with transesophageal echocardiography. Catheter Cardiovasc Interv 2001; 52: 194-9.

7. Koenig P, Cao QL, Heitschmidt M, Waight DJ, Hijazi ZM. Role of intracardiac echocardiographic guidance in transcatheter closure of atrial septal defects and patent foramen ovale using the Amplatzer device. J Interv Cardiol 2003; 16: 51-62.

8. Koenig PR, Abdulla RI, Cao QL, Hijazi ZM. Use of intracardiac echocardiography to guide catheter closure of atrial communications. Echocardiography 2003; 20: 781-7. (Review)

9. Bartel T, Konorza T, Neudorf U, et al. Intracardiac echocardiography: an ideal guiding tool for device closure of interatrial communications. Eur J Echocardiogr 2005; 6: 92-6. 
10. Mullen MJ, Dias BF, Walker F, Siu SC, Benson LN, McLaughlin PR. Intracardiac echocardiography guided device closure of atrial septal defects. J Am Coll Cardiol 2003; 41: 285-92.

11. Chan KC, Godman MJ, Walsh K, Wilson N, Redington A, Gibbs JL. Transcatheter closure of atrial septal defect and interatrial communications with a new self expanding nitinol double disc device (Amplatzer septal occluder): multicentre UK experience. Heart 1999; 82: 300-6.

12. Fischer G, Kramer HH, Stieh J, Harding P, Jung O. Transcatheter closure of secundum atrial septal defects with the new selfcentering Amplatzer Septal Occluder. Eur Heart J 1999; 20: 541-9.

13. Masura J, Gavora P, Formanek A, Hijazi ZM. Transcatheter closure of secundum atrial septal defects using the new selfcentering amplatzer septal occluder: initial human experience. Cathet Cardiovasc Diagn 1997; 42: 388-93.

14. Berger F, Ewert P, Abdul-Khaliq H, Nürnberg JH, Lange PE. Percutaneous closure of large atrial septal defects with the Amplatzer Septal Occluder: technical overkill or recommendable alternative treatment? J Interv Cardiol 2001; 14: 63-7.

15. Zanchetta M. On-line intracardiac echocardiography alone for Amplatzer Septal Occluder selection and device deployment in adult patients with atrial septal defect. Int J Cardiol 2004; 95: 61-8.

16. Carlson KM, Justino H, O'Brien RE, et al. Transcatheter atrial septal defect closure: modified balloon sizing technique to avoid overstretching the defect and oversizing the Amplatzer septal occluder. Catheter Cardiovasc Interv 2005; 66: 390-6.
17. Zhu W, Cao QL, Rhodes J, Hijazi ZM. Measurement of atrial septal defect size: a comparative study between three-dimensional transesophageal echocardiography and the standard balloon sizing methods. Pediatr Cardiol 2000; 21: 465-9.

18. Zanchetta M, Onorato E, Rigatelli G, et al. Intracardiac echocardiography-guided transcatheter closure of secundum atrial septal defect: a new efficient device selection method. J Am Coll Cardiol 2003; 42: 1677-82.

19. Zanchetta M, Pedon L, Rigatelli G, et al. Intracardiac echocardiography evaluation in secundum atrial septal defect transcatheter closure. Cardiovasc Intervent Radiol 2003; 26: 52-7.

20. Zanchetta M, Rigatelli G, Pedon L, et al. Transcatheter atrial septal defect closure assisted by intracardiac echocardiography: 3-year follow-up. J Interv Cardiol 2004; 17: 95-8.

21. Alsaileek AA, Omran A, Godman M, Najm HK. Echocardiographic visualization of laceration of atrial septum during balloon sizing of atrial septal defect. Eur J Echocardiogr 2007; 8: 155-7.

22. Bonvini RF, Sigwart U, Verin V. Interatrial septum rupture during balloon measurement of a patent foramen ovale in a young patient presenting cryptogenic stroke. Catheter Cardiovasc Interv 2007; 69: 274-6.

23. Fu YC, Bass J, Amin Z, et al. Transcatheter closure of perimembranous ventricular septal defects using the new Amplatzer membranous VSD occluder: results of the U.S. phase I trial. J Am Coll Cardiol 2006; 47: 319-25. 